\title{
Rapid screening of the antimicrobial efficacy of Ag zeolites
}

\author{
L. Tosheva ${ }^{*}$, a, S. Belkhair ${ }^{\text {a }}$, M. Gackowski ${ }^{\text {a,b }}$, S. Malic ${ }^{\text {a }}$, N. Al-Shanti ${ }^{\text {a }}$ and J. Verran ${ }^{\mathrm{a}}$
}

${ }^{\text {a }}$ Faculty of Science and Engineering, Manchester Metropolitan University, Chester Street, Manchester, M1 5GD, United Kingdom. E-mail: 1.tosheva@mmu.ac.uk

${ }^{\mathrm{b}}$ Jerzy Haber Institute of Catalysis and Surface Chemistry, Polish Academy of Sciences, Niezapominajek 8, 30-239 Krakow, Poland.

\begin{abstract}
A semi-quantitative screening method was used to compare the killing efficacy of $\mathrm{Ag}$ zeolites against bacteria and yeast as a function of the zeolite type, crystal size and concentration. The method, which substantially reduced labor, consumables and waste and provided an excellent preliminary screen, was further validated by quantitative plate count experiments. Two pairs of zeolite $X$ and zeolite beta with different sizes (ca. 200 $\mathrm{nm}$ and $2 \mu \mathrm{m}$ for zeolite $\mathrm{X}$ and ca. 250 and $500 \mathrm{~nm}$ for zeolite beta) were tested against Escherichia coli (E. coli) and Candida albicans (C. albicans) at concentrations in the range $0.05-0.5 \mathrm{mg} \mathrm{ml}^{-1}$. Reduction of the zeolite crystal size resulted in a decrease in the killing efficacy against both microorganisms. The semi-quantitative tests allowed convenient optimization of the zeolite concentrations to achieve targeted killing times. Zeolite beta samples showed higher activity compared to zeolite X despite their lower Ag content, which was attributed to the higher concentration of silver released from zeolite beta samples. Cytotoxicity measurements using peripheral blood mononuclear cells (PBMCs) indicated that Ag zeolite X was more toxic than Ag zeolite beta. However, the trends for the dependence of cytotoxicity on zeolite crystal size at different zeolite concentrations were different for the two zeolites and no general conclusions about zeolite cytotoxicity could be drawn from these experiments. This
\end{abstract}


result indicates a complex relationship, requiring the necessity for individual cytotoxicity measurements for all antimicrobial applications based on the use of zeolites.

Keywords: Silver zeolites; antimicrobial; killing efficacy; crystal size; cytotoxicity 


\section{Introduction}

Antimicrobial resistance is a global threat resulting in delayed recovery of patients and increased risk of spreading of infectious diseases, increased healthcare expenditures and increased mortality rates. Considering the lack of new antibiotics, therapeutic prevention of diseases is one of the main strategies considered to fight drug resistance. Silver-based materials have emerged as one of the most promising alternatives to combat multi-drug resistant microorganisms [1]. The range of materials, mechanism of antibacterial action, issues and challenges in the use of silver as antibacterial agent have been discussed in several excellent reviews [2-5]. Amongst silver carriers used, zeolites have many attractive properties, such as: (i) rigid frameworks with high chemical, mechanical and thermal stability and (ii) high surface areas and micropore systems allowing slow silver release. Their ion-exchange properties enable the application of simple synthetic protocols for introduction of silver ions with the possibility for subsequent silver reduction to form silver nanoparticles. Currently, there are 231 zeolite structures approved by the Zeolite Structure Commission [6]. Only a handful of these structures have been tested as silver supports for antimicrobial applications, providing a scope for extensive future research. Such research will also inform the design of innovative multifunctional materials based on Ag zeolites, examples of which can already be found in the literature [7].

There are a number of factors affecting the antimicrobial activity of silver zeolites. Direct comparison of different studies is often difficult because of the different testing methods used such as the agar well diffusion and fluorescence assays or the culture growth suppression spectrophotometric method [8-10]. The antibacterial activity of Ag zeolites increased with increasing the Ag content in parent ETS-10, A and EMT 
zeolites [11-13]. In each of these works, six Ag zeolite samples were tested, three after Ag ion-exchange at different levels, and three after subsequent silver reduction. The samples prepared after Ag reduction showed higher activity [11,13]. Additionally, we have demonstrated that the design of the microbiology tests, for instance the selection of a growth medium, can be significant for the results obtained [13]. Further, the antimicrobial properties of Ag zeolites were dependent on the zeolite structure (pore sizes, pore channel systems) rather than the amount of silver exchanged in the zeolite [14]. ZSM-5 containing only $0.2 \mathrm{wt} . \% \mathrm{Ag}$ has been reported to be active against Staphylococcus aureus [15]. Even variations in the $\mathrm{Si} / \mathrm{Al}$ ratio within the same zeolitetype structure, e.g., zeolite X and zeolite Y, FAU-type structure, were found to influence the minimum inhibitory concentration against bacteria [16]. The antimicrobial activity of Ag zeolites could be further improved by introducing a second metal such as $\mathrm{Zn}[17]$.

For biomedical applications, the determination of the cytotoxicity of Ag zeolites is of paramount importance, but such studies are rarely carried out. Greulich et al. have reported that the toxic effect of silver towards bacterial and mammalian cells is similar [18]. Zeolites themselves have shown cytotoxicity depending on zeolite type, dose and cells used $[19,20]$. Ultrasmall, 8-18 nm EMT and LTL, zeolites have demonstrated absence of cytotoxicity at concentrations between 100 and $400 \mu \mathrm{g} \mathrm{ml}^{-1}$ [21]. Two recent reviews discuss aspects of nanozeolite cytotoxicity in more detail $[22,23]$. In addition, an acute toxicity has been reported for silver ions in nanosized EMT-type zeolites, however the tests were performed on animal cell lines and human tumor cells [24].

Nanozeolites comprise one of the major developments in the zeolite area since their first synthesis in the early 1990s [25]. There are examples of their superior 
performance compared to conventional micron-sized zeolites in traditional applications such as catalysis. In addition, they have shown potential for many emerging applications [23]. The effect of zeolite crystal size on the antimicrobial properties of Ag zeolites has not been systematically studied so far. Considering the particulars of synthesis approaches used to prepare such zeolites, for example high-speed centrifugation during their post-synthesis purification and metal ion-exchange, such a study will be highly beneficial to assess their profitability as antimicrobials. Another objective of the present paper was to develop a reliable microbiology method allowing screening of a large number of zeolite samples for quick assessment of their microbial killing efficacy to inform the selection of zeolite samples, e.g., zeolite type and crystal size, and to determine optimum zeolite concentrations for a particular microbiology application. Escherichia coli (E. coli) was used as a model for Gram-negative bacteria [26]. The yeast Candida albicans (C. albicans), a recognized human pathogen [27], that has shown to be less sensitive to Ag zeolites compared to bacteria [28], was also used. In addition, the cytotoxicity of the Ag-exchanged zeolite $\mathrm{X}$ and zeolite beta samples was determined using human peripheral blood mononuclear cells isolated from healthy volunteers' human blood.

\section{Materials and methods}

\subsection{Zeolite synthesis}

Zeolite X (X1 and X2) and zeolite beta (B1 and B2) samples were synthesized by hydrothermal treatment (Table 1). Sample X1 was prepared from a gel with the molar composition $5.5 \mathrm{Na}_{2} \mathrm{O}: 1.0 \mathrm{Al}_{2} \mathrm{O}_{3}: 4.0 \mathrm{SiO}_{2}: 190 \mathrm{H}_{2} \mathrm{O}$ using $\mathrm{NaAlO}_{2}$ (Fischer), $\mathrm{NaOH}$ (Alfa Aesar), fumed silica (Aerosil 200, Degussa) and distilled water [29]. The mixture was stirred at room temperature for $24 \mathrm{~h}$, transferred to a polypropylene reactor 
and hydrothermally treated at $60{ }^{\circ} \mathrm{C}$ for 4 days. After the synthesis, the sample was purified by three-times centrifugation and redispersion in distilled water and dried at 60 ${ }^{\circ} \mathrm{C}$ overnight. Sample X2 was prepared from a gel with the molar composition $8 \mathrm{NaOH}$ : $0.2 \mathrm{Al}_{2} \mathrm{O}_{3}: 1.0 \mathrm{SiO}_{2}: 200 \mathrm{H}_{2} \mathrm{O}$ as described previously [30]. The precursor gel was transferred to a Teflon-lined autoclave and treated at $110{ }^{\circ} \mathrm{C}$ for $3 \mathrm{~h}$.

Zeolite beta samples were synthesized form a clear precursor solution with the molar composition $0.3 \mathrm{Na}_{2} \mathrm{O}: 9 \mathrm{TEAOH}: 0.5 \mathrm{Al}_{2} \mathrm{O}_{3}: 25 \mathrm{SiO}_{2}: 489 \mathrm{H}_{2} \mathrm{O}$ using aluminum isopropoxide (Alfa Aesar), silica sol (Bindzil 30/220, EKA Chemicals), tetraethylammonium hydroxide (20 wt.\% aqueous solution, Alfa Aesar) and distilled water [31]. Sample B1 was prepared by hydrothermal treatment at $150{ }^{\circ} \mathrm{C}$ for $48 \mathrm{~h}$, whereas for sample B2 the crystallization was performed at $170{ }^{\circ} \mathrm{C}$ for $38 \mathrm{~h}$. Both samples were purified by three-times centrifugation and redispersion in distilled water and dried at $60{ }^{\circ} \mathrm{C}$ overnight. The organic template was removed by calcination at 550 ${ }^{\circ} \mathrm{C}$ for $5 \mathrm{~h}$ after heating to that temperature at a rate of $10{ }^{\circ} \mathrm{C} \mathrm{min}^{-1}$.

The as-made zeolite samples were ion-exchanged with silver as described previously [28]. Each sample was mixed with a $0.05 \mathrm{M} \mathrm{AgNO}_{3}$ solution $\left(\mathrm{AgNO}_{3}\right.$, $99+\%$, Alfa Aesar) at a solution to sample weight ratio of 20 and stirred for $72 \mathrm{~h}$ in the dark. The samples were then centrifuged three times (6000 rpm, $10 \mathrm{~min}$ ) and redispersed in distilled water, and finally dried at $60{ }^{\circ} \mathrm{C}$ overnight.

\subsection{Characterization methods}

Zeolite crystal sizes were determined with a Carl Zeiss Ltd 40VP Supra Scanning Electron Microscope (SEM). The particle sizes of samples X1, B1 and B2 were also verified by dynamic light scattering (DLS) using a Zetasizer Nano ZS instrument with a $173^{\circ}$ backscattering angle geometry. Semi-quantitative chemical 
analysis was performed on uncoated sample pellets by energy-dispersive X-ray spectroscopy (EDS) using an Apollo 40 SDD detector (EDAX Inc.). The average of five measurements was used in the determinations. X-ray diffraction (XRD) patterns were collected with a PANalytical X'Pert X-ray diffractometer (XRD) employing $\mathrm{Cu} \mathrm{K}_{\alpha}$ radiation (40 kV and $30 \mathrm{~mA})$ and a PIXcell detector. Nitrogen adsorption isotherms of the zeolite samples prior to silver ion-exchange were recorded on a Micromeritics ASAP 2020 surface area analyzer at $-196{ }^{\circ} \mathrm{C}$. Samples were degassed at $300{ }^{\circ} \mathrm{C}$ overnight prior to analysis. BET areas were calculated using the BET equation, whereas external surface areas $\left(\mathrm{S}_{\mathrm{EXT}}\right)$ and micropore volumes $\left(\mathrm{V}_{\mu}\right)$ were determined by the $\mathrm{t}$-plot method. BJH pore-size distributions were determined from the desorption branch of the isotherms.

\subsection{Antimicrobial tests}

A single colony of E. coli (ATCC 8739) from a freshly cultured nutrient agar (Oxoid, UK) plate was removed using a sterile loop and inoculated in $100 \mathrm{ml}$ of sterile nutrient broth (Oxoid, UK). Broth was incubated for $18 \mathrm{~h}$ at $37{ }^{\circ} \mathrm{C}$ in a rotary shaker incubator set at $150 \mathrm{rpm}$. The liquid culture was centrifuged at $3000 \mathrm{rpm}$ for $10 \mathrm{~min}$ so that cells formed a pellet, which was re-suspended in distilled water. An optical density of 1.0 at $540 \mathrm{~nm}$ wavelength was obtained (Jenway 6305 Spectrophotometer, UK), corresponding to approximately $10^{8}$ colony-forming units (CFU) per $\mathrm{ml}$. The same procedure was applied for C. albicans (NCYC 1363) but the overnight growth was performed in Sabouraud dextrose liquid medium and the approximate starting concentration of the yeast suspension was $10^{5}$ colony forming units (CFU) per ml. $25 \mu \mathrm{l}$ of the bacterial or yeast suspensions were added to $20 \mathrm{ml}$ of $0.5,0.1$ and $0.05 \mathrm{mg} \mathrm{ml}^{-1}$ Ag zeolite suspensions and vortexed immediately for 30 s. Corresponding Ag-free 
samples were used for control experiments. The samples were incubated at $37^{\circ} \mathrm{C}$ in a rotary shaker incubator set at $150 \mathrm{rpm}$ and a sample was taken immediately after mixing (zero min) and then every min for up to $7 \mathrm{~min}$ with vortexing immediately before sampling. A single drop $(0.02 \mathrm{ml})$ of sample was added to one segment of thioglycollate agar (ThGA) plate divided into 8 segments. The ThGA plate was prepared by mixing thioglycollate broth with $1.2 \mathrm{wt} . \%$ technical agar (Oxoid, UK). The role of this agar is to neutralize the bactericidal effect of silver at the selected sampling times [32]. All tests were carried out in duplicate. The plates were incubated overnight at $37^{\circ} \mathrm{C}$ and then visually evaluated to compare the silver zeolites' killing efficacy as a function of the zeolite crystal size, zeolite type and zeolite concentration indicated by $+/$ - growth.

The release of silver from the zeolite samples was measured in the mother liquor immediately after the 7-min semi-quantitative tests. The suspensions were centrifuged at $3000 \mathrm{rpm}$ for $10 \mathrm{~min}$, the pellet formed was discarded and the supernatant was analyzed on a Thermo Scientific iCAP6300 Duo inductively coupled plasma optical emission spectrometer (ICP-OES) using the Ag $328.1 \mathrm{~nm}$ analytical wavelength.

Quantitative plate count experiments using E. coli were performed to verify the conclusions drawn by the semi-quantitative microbiology tests. The E. coli suspension $\left(25 \mu \mathrm{l}, 10^{8} \mathrm{CFU} \mathrm{m} \mathrm{m}^{-1}\right)$ was added to $5 \mathrm{ml}$ of $0.5 \mathrm{mg} \mathrm{ml}^{-1}$ suspensions of the Ag zeolite samples. Ag-free zeolite $\mathrm{X}$ and zeolite beta samples were used for negative control experiments. The samples were incubated at $37^{\circ} \mathrm{C}$ in a rotary shaker incubator set at $150 \mathrm{rpm}$. A sample $(100 \mu \mathrm{l})$ was taken every min between 0 and $7 \mathrm{~min}$ with vortexing prior to sampling, inoculated in $900 \mu 1$ phosphate buffer saline (PBS) and then serially diluted ten-fold in the range $10^{-2}$ to $10^{-4}$. Each diluted sample $(100 \mu \mathrm{l})$ was inoculated onto duplicate plates of ThGA, spread, dried and incubated overnight at $37{ }^{\circ} \mathrm{C}$. The 
number of colonies was counted for the dilution giving the highest countable number of cells and the average CFU per ml of original suspension was then calculated. It is important to mention that there was a delay of approximately 10 min between sampling and plating onto the ThGA plates due to dilution. This delay time was consistent across all samples studied.

\subsection{Cytotoxicity tests}

Peripheral blood mononuclear cells (PBMCs) were isolated from donated blood of healthy individuals ( $\mathrm{n}=3$, one female and two males, age between $20-25$ years old) as previously described [33]. An in house ethical approval protocol (Manchester Metropolitan University) was followed. The blood (20 ml) was carefully layered on the same volume of Ficoll-Paque PLUS (GE Healthcare Life Sciences, Buckinghamshire, UK). After 40 min centrifugation at $400 \times \mathrm{g}$ at $18-20^{\circ} \mathrm{C}$, the peripheral blood mononuclear cells layer was carefully removed and washed twice with RPMI-1640 medium. Isolated PBMCs $\left(3 \times 10^{5}\right.$ per well) were cultured in flat-bottomed 24-well plates [34]. PBMCs were grown in RPMI-1640 medium containing Ag zeolite (X1, X2, B1 and B2) samples of different concentrations (1, 0.5, 0.1, 0.05 and $\left.0.001 \mathrm{mg} \mathrm{ml}^{-1}\right)$, $10 \%(\mathrm{v} / \mathrm{v})$ human $\mathrm{AB}$ serum and $1 \%$ penicillin/streptomycin at $37{ }^{\circ} \mathrm{C}$ in $5 \% \mathrm{CO}_{2}$. Three experiments (blood from three volunteers) were performed for each zeolite concentration with 8 readings obtained for X1 and X2 samples (one duplicate and two triplicates) and 7 readings obtained for B1 and B2 samples as well as the untreated cells (two duplicates and one triplicate) The amount of Ag zeolite needed to obtain the above concentrations was firstly added to PBS and vortexed. After two weeks, the samples were centrifuged and the supernatant was used in the cytotoxicity tests. All cultures 
were supplemented with $50 \mathrm{U} \mathrm{ml}^{-1}$ human recombinant interleukin-2 (IL-2) (R\&D Systems Abingdon, UK).

Flow cytometry, which is widely used to determine apoptotic population using pre-G1, was employed to measure the cytotoxic effect of silver zeolites on PBMCs apoptosis, following $48 \mathrm{~h}$ in culture [35]. The PBMCs were harvested and washed in PBS prior to fixing at $-20{ }^{\circ} \mathrm{C}$ in $75 \%$ ethanol. After a minimum of $24 \mathrm{~h}$, the PBMCs were washed twice in PBS and re-suspended with gentle vortexing in propidium iodide labelling buffer $\left(50 \mu \mathrm{g} \mathrm{ml}^{-1}\right.$ propidium iodide, $0.1 \%$ sodium citrate, $20 \mu \mathrm{g} \mathrm{ml}^{-1}$ ribonuclease $\mathrm{A}, 0.3 \%$ Nonidet $\mathrm{P}-40, \mathrm{pH} 8.3$ ) at approximately $1 \times 10^{6}$ cells $\mathrm{ml}^{-1}$. The PBMCs were analyzed using a Becton Dickinson FACSCalibur flow cytometer. Data were analyzed using Cell Quest software (Becton Dickinson, Oxford, UK). Statistical significance of the results for zeolite-treated cells and untreated cells was determined with a one-way ANOVA followed by Tukey-Kramerith multiple post hoc analysis. All results are presented as mean \pm standard deviation of the mean $(\mathrm{N}=7$ or 8 as discussed above). Results were considered as statistically significant when $\mathrm{p}<0.05$.

\section{Results and discussion}

\subsection{Zeolite characteristics}

SEM was used to determine the particle size distributions of the samples used in this study (Fig. 1) and data is presented in Table 1. Sample X1 contained nanosized crystals with sizes of about $200 \mathrm{~nm}$, whereas the crystal sizes of sample X2 were one order of magnitude larger (Fig. 1 a,b). B2 crystals were about two times larger compared to B1 crystals. The crystal sizes of samples X1, B1 and B2 were also measured by DLS (Fig. S1, Supporting Information) and the average Z sizes determined were 258,254 and $576 \mathrm{~nm}$, respectively. 
The samples were further analyzed by XRD (Fig. S2). The XRD analysis confirmed the presence of zeolite $\mathrm{X}$ and zeolite beta, correspondingly, as single phases. The XRD peak intensities of the X1 sample were considerably lower compared to these of X2 and the peaks were broader. Both effects can be attributed to the reduction of crystal sizes in X1 to nano-dimensions [36]. The Ag ion-exchange resulted in changes in the relative intensities of the (220), (311) and (331) faujasite peaks in the XRD patterns of the Ag-exchanged zeolite $\mathrm{X}$ compared to the NaX sample in accordance with our previous results (not shown) [28]. No changes were observed in the XRD patterns of the zeolite beta samples after the Ag ion-exchange and both zeolite beta samples were highly crystalline (Fig. S2).

Differences in the textural characteristics of the different samples were observed according to nitrogen adsorption data (Fig. S3). All zeolites showed type I isotherms with a hysteresis loop at high relative pressures in the isotherms of samples X1 and B1 due to interparticle textural porosity associated with small particle sizes [23]. The external surface areas increased with a decrease in the particle size accordingly (Table 1). Similar micropore volumes were determined for samples $X 1$ and $X 2$, which were typical of a highly crystalline FAU-type zeolite [23]. The pore-size distributions further outlined the differences in the secondary (non-zeolite) porosity of the samples (Fig, S3, inserts). Sharp mesoporous peaks centered around 45-50 nm were present in the poresize distribution plots of samples X1 and B1.

\subsection{Antimicrobial tests}

The zeolite samples were compared directly in terms of their antimicrobial efficacy by semi-quantitative tests. Three different zeolite concentrations were selected for the tests based on our previous results [37]. The Ag zeolite samples at different 
concentrations were tested against E. coli and C. albicans. The Ag-free samples used as controls did not show any antimicrobial activity. The results for zeolite concentrations of $0.5 \mathrm{mg} \mathrm{ml}^{-1}$ and both microorganisms are shown in Figs. 2 and 3. The number of viable E. coli colonies visually decreased with time for both zeolite X samples (Fig. 2), although this was less apparent in the presence of the nanosized X1 sample after 7 min. No colonies could be seen at the 7 min sampling time for the micron-sized sample X2. The zeolite beta samples were more efficient compared to zeolite $\mathrm{X}$ and killed E. coli within 2 min (Fig. 2). An increase in the crystal size increased the killing efficacy for this zeolite as well. The experiments performed with two additional zeolite concentrations, 0.05 and $0.1 \mathrm{mg} \mathrm{ml}^{-1}$, showed similar trends regarding the influence of the crystal size on the killing efficacy (Supporting Information, Fig. S4 and Fig. S5). Zeolite $\mathrm{X}$ samples were not active at $0.05 \mathrm{mg} \mathrm{ml}^{-1}$ concentration within the 7-min test period (Fig. S4). At $0.1 \mathrm{mg} \mathrm{ml}^{-1}$ concentration, sample X2 was clearly more active than sample X1, although growth was still detected after 7 min using this sample (Fig. S4). In the case of zeolite beta, no growth was observed after 7 and 6 min for B1 and B2, respectively at $0.05 \mathrm{mg} \mathrm{ml}^{-1}$ concentration, and after 6 and $5 \mathrm{~min}$, respectively at $0.1 \mathrm{mg}$ $\mathrm{ml}^{-1}$ concentration (Fig. S5).

The $0.5 \mathrm{mg} \mathrm{ml}^{-1}$ zeolite concentration was also tested against C. albicans (Fig. 3). The results also suggest that larger-sized zeolites are more efficient against yeast. Zeolite beta was again more active compared to zeolite X. It is worth noting that owing to the much larger $C$. albicans cells and their lower initial concentration of test suspension compared to E. coli, the results for the two microorganisms cannot be compared directly. 
The silver release data is provided in Table 2. The amount of released silver was higher for all zeolite beta samples despite their lower Ag loading, which could explain their higher activity. Daniel et al. have shown that there are distinct differences in the estimated number and strength of adsorption sites for Xe in silver-modified zeolites $\mathrm{X}$ and beta, suggesting that differences could be expected for their Ag release profiles [38]. Extra- framework aluminum has also been speculated to hinder the silver release [14]. Additionally, smaller crystals may be aggregated to a larger extent in the testing medium to obstruct the release of silver and lower concentrations of Ag were measured for samples X1 and B1 compared to X2 and B2, respectively.

The semi-quantitative microbiology tests indicated that the zeolite killing efficacy was higher for zeolite beta compared to zeolite $\mathrm{X}$ and it increases with an increase in the zeolite crystal size. These conclusions were further verified by performing quantitative plate count experiments using E. coli. The results from these experiments confirm that zeolite beta is more active compared to zeolite $\mathrm{X}$ and also that the larger-sized crystals are more efficient (Fig. 4). The reduction in labor, consumables and waste using the semi-quantitative tests prior to quantitative measurements is remarkable. For example, the inoculation of E. coli on ThGA plates using the five zeolite samples (control, X1, X2, B1 and B2) took 35 min and required 10 plates in the case of the semi-quantitative procedure, and 125 min and 320 plates, respectively when, the quantitative measurements were employed. Considering the varying results for the dependence of the killing efficacy on the zeolite concentration, crystal size and zeolite type, the use of the semi-quantitative procedure offers unique advantages in microbiology experiments employing zeolites and related materials. Killing times are also organism-dependent and many tests are usually required to select appropriate 
concentrations and sampling times for test materials. The screening semi-quantitative method used in this work increased the efficiency of microbiology tests substantially.

\subsection{Cytotoxicity tests}

For cytotoxicity tests, PBMCs were cultured for 2 days under the conditions described in Experimental. At the end of cell treatments, PBMCs were subjected to flow cytometry analysis for Pre-G1 (apoptosis marker) and results are shown in Fig. 5. According to the results, all zeolites were non-toxic at concentrations of $0.05 \mathrm{mg} \mathrm{ml}^{-1}$ and below. Moreover, zeolites X2, B1 and B2 samples were non-toxic even at higher concentrations, $0.1 \mathrm{mg} \mathrm{ml}^{-1}$ for $\mathrm{X} 2$ and $\mathrm{B} 2$ and $0.5 \mathrm{mg} \mathrm{ml}^{-1}$ for $\mathrm{B} 1$. The zeolite beta samples were highly active against both microorganisms at these concentrations (Figs. 2, 3 and Fig. S5, Supporting Information). The higher toxicity of zeolite X samples could not be explained by the amount of Ag released, which was lower compared to that for beta (Table 2). Thus, a possible explanation might be the higher aluminum content and associated cytotoxicity of the zeolite itself [20]. The cytotoxicity tests indicate that the relationship between the Ag zeolites and cytotoxicity is complex and depends on many factors such as zeolite type, zeolite concentration and zeolite characteristics.

\section{Conclusion}

The effect of zeolite structure, crystal size and concentration on the antimicrobial efficacy of two Ag zeolites, zeolite X and zeolite beta, was studied by a semi-quantitative method. Zeolite beta was found to be more efficient compared to zeolite $\mathrm{X}$ and no viable cells of $E$. coli and C. albicans were observed within 2 min of incubation with both microorganisms using zeolite concentrations of $0.5 \mathrm{mg} \mathrm{ml}^{-1}$. Reduction of crystal size resulted in an increase in E. coli killing time as a result of reduced Ag content released to the medium by the smaller crystals. The results obtained 
by the semi-quantitative antimicrobial tests used were verified by the application of a quantitative count plate experiments. The semi-quantitative procedure reported here substantially reduces labor, consumables and waste, and can be adopted for testing other materials. Cytotoxicity measurements showed that zeolite $\mathrm{X}$ was more toxic compared to zeolite beta, and the effect was more pronounced for the nanosized zeolite X. The results reported here will be of interest when selecting silver zeolites for biomedical applications, particularly when fast antimicrobial response is required, to optimize the zeolite carrier in terms of structural and textural characteristics, zeolite concentration and antimicrobial metal concentration and form.

\section{Acknowledgements}

MG is grateful to Erasmus + and the EU Human Capital Operation Program, Polish Project No. POKL.04.0101-00-434/08-00, for financial support.

\section{Appendix A. Supplementary data}

Supplementary data associated with this article can be found, in the online version, at

\section{References}

[1] M.K. Rai, S.D. Deshmukh, A.P. Ingle, A.K. Gade, J. Appl. Microbiol. 112 (2012) $841-852$

[2] J.R. Morones, J.L. Elechiguerra, A. Camacho, K. Holt, J.B. Kouri, J.T. Ramírez, M.J. Yacaman, Nanotechnology 16 (2005) 2346-2353.

[3] S. Chernousova, M. Epple, Angew. Chem. Int. Ed. 52 (2013) 1636-1653.

[4] S. Eckhardt, P.S. Brunetto, J. Gagnon, M. Priebe, B. Giese, K.M. Fromm, Chem. Rev. 113 (2013) 4708-4754.

[5] L. Rizzello, P.P. Pompa, Chem. Soc. Rev. 43 (2014) 1501-1518. 
[6] Database of Zeolite Structures, http://www.iza-structure.org/databases/. Accessed 6 July 2016.

[7] V.V. Singh, B. Jurado-Sánchez, S. Sattayasamitsathit, J. Orozco, J. Li, M. Galarnyk, Y. Fedorak, J. Wang, Adv. Funct. Mater. 25 (2015) 2147-2155.

[8] S. Demirci, Z. Ustaoğlu, G.A. Yilmazer, F. Sahin, N. Bac, Appl. Biochem. Biotechnol. 172 (2014) 1652-1662.

[9] K.A. Rieger, H.J. Cho, H.F. Yeung, W.Fan, J.D. Schiffman, ACS Appl. Mater. Interfaces 8 (2016) 3032-3040.

[10] K.K. Krishnani, Y. Zhang, L. Xiong, Y. Yan, R. Boopathy, A. Mulchandani, Bioresource Technol. 117 (2012) 86-91.

[11] L. Lv, Y. Luo, W.J. Ng, X.S. Zhao, Micropor. Mesopor. Mater. 120 (2009) 304309.

[12] D. Jiraroj, S. Tungasmita, D.N. Tungasmita, Powder Technol. 264 (2014) 418422.

[13] B. Dong, S. Belkhair, M. Zaarour, L. Fisher, J. Verran, L. Tosheva, R. Retoux, J.-P. Gilson, S. Mintova, Nanoscale 6 (2014) 10859-10864.

[14] P. Saint-Cricq, Y. Kamimura, K. Itabashi, A. Sugawara-Narutaki, A. Shimojima, T. Okubo, Eur. J. Inorg. Chem. 21 (2012) 3398-3402.

[15] P. Lalueza, M. Monzón, M. Arruebo, J. Santamaria, Chem. Commun. 47 (2011) 680-682.

[16] L. Ferreira, A.M. Fonseca, G. Botelho, C. Almeida-Aguiar, I.C. Neves, Micropor. Mesopor. Mater. 160 (2012) 126-132.

[17] L. Ferreira, J.F. Guedes, C. Almeida-Aguiar, A.M. Fonseca, I.C. Neves, Colloid Surface B 142 (2016) 141-147. 
[18] C. Greulich, D. Braun, A. Peetsch, J. Diendorf, B. Siebers, M. Epple, M. Köller, RSC Adv. 2 (2012) 6981-6987.

[19] A. Petushkov, J. Intra, J.B. Graham, S.C. Larsen, A.K. Salem, Chem. Res. Toxicol. 22 (2009) 1359-1368.

[20] T. Kihara, Y. Zhang, Y. Hu, Q. Mao, Y. Tang, J. Miyake, J. Biosci. Bioeng. 111 (2011) 725-730.

[21] S. Laurent, E.-P. Ng, C. Thirifays, L. Lakiss, G.-M. Goupil, S. Mintova, C. Burtea, E. Oveisi, C. Hébert, M. de Vries, M.M. Motazacker, F. Rezaee, M. Mahmoudi, Toxicol. Res. 2 (2013) 270-279.

[22] S.E. Lehman, S. C. Larsen, Environ. Sci.: Nano 1 (2014) 200-213.

[23] S. Mintova, M. Jaber, V. Valtchev, Chem. Soc. Rev. 44 (2015) 7207-7233.

[24] C. Anfray, B. Dong, S. Komaty, S. Mintova, S. Valable, ACS Appl. Mater. Interfaces (2017), DOI: 10.1021/acsami.7b00265.

[25] V. Valtchev, L. Tosheva, Chem. Rev. 113 (2013) 6734-6760.

[26] I. Sondi, B. Salopek-Sondi, J. Colloid. Interf. Sci. 275 (2004) 177-182.

[27] M.J. McCullough, B.C. Ross, P.C. Reade, Int. J. Oral Maxillofac. Surg. 25 (1996) 136-144.

[28] S. Belkhair, M. Kinninmonth, L. Fisher, B. Gasharova, C.M. Liauw, J. Verran, B. Mihailova, L. Tosheva, RSC Adv. 5 (2015) 40932-40939.

[29] M. Ansari, A. Aroujalian, A. Raisi, B. Dabir, M. Fathizadeh, Adv. Powder Technol. 25 (2014) 722-727.

[30] V.P. Valtchev, K.N. Bozhilov, J. Phys. Chem. B 108 (2004) 15587-15598.

[31] B.J. Schoeman, E. Babouchkina, S. Mintova, V.P. Valtchev, J. Sterte, J. Porous Mater. 8 (2001) 13-22. 
[32] R.C. Tilton, B. Rosenberg, Appl. Environ. Microbiol. 35 (1978) 1116-1120.

[33] R.J. Garland, N. El-Shanti, S.E. West, J.P. Hancock, N.J. Goulden, C.G.

Steward, A.W. Rowbottom, Scand. J. Immunol. 55 (2002) 61-69.

[34] N. Al-Shanti, C.E. Stewart, J. Cell.Biochem. 113 (2012) 923-933.

[35] X.-W. Zhang, C. Qing, B. Xu, Anti-Cancer Drugs 10 (1999) 569-576.

[36] S.C. Larsen, J. Phys. Chem. C 111 (2007) 18464-18474.

[37] L. Tosheva, A. Brockbank, B. Mihailova, J. Sutula, J. Ludwig, H. Potgieter, J. Verran, J. Mater. Chem. 22 (2012) 16897-16905.

[38] C. Daniel, A. Elbaraoui, S. Aquado, M.-A. Springuel-Huet, A. Nossov, J.-P. Fontaine, S. Topin, T. Taffary, L. Deliere, Y. Schuurman, D. Farrusseng, J. Phys. Chem. C 117 (2013) 15122-15129. 


\section{Figure captions}

Figure 1. SEM images of: (a) X1, (b) X2, (c) B1, and (d) B2.

Figure 2. Spot inoculation of E. coli onto ThGA plates (in duplicate) following $1 \mathrm{~min}$ interval exposure to the different zeolite samples. Each drawn segment on the plates above corresponds to one min sampling time; the first sample (top) is taken directly after mixing ( 0 min) with clockwise inoculation over time.

Figure 3. Spot inoculation of C. albicans onto ThGA plates (in duplicate) following 1 min interval exposure to the different zeolite samples. Each drawn segment on the plates above corresponds to one min sampling time; the first sample (top) is taken directly after mixing (0 min) with clockwise inoculation over time.

Figure 4. Antibacterial effect of: (a) zeolite X and (b) zeolite beta on E. coli over 7-min exposure. The asterisks * in (a) indicates fewer than 20 colonies at $10^{-1}$ dilution.

Figure 5. Cytotoxic effect of silver zeolite samples of different concentrations on freshly isolated cultured PBMCs. Asterisks (*) indicate significant differences in comparison with the control $(* \mathrm{p}<0.05, * * \mathrm{p}<0.01, * * * \mathrm{p}<0.001)$. 
Table 1. Physicochemical characteristics of the Ag zeolite samples used.

\begin{tabular}{llllllll}
\hline Sample & $\begin{array}{l}\text { Zeolite } \\
\text { type }\end{array}$ & $\begin{array}{l}\text { Crystal size } \\
(\mathrm{SEM})\end{array}$ & $\begin{array}{l}\mathrm{Si} / \mathrm{Al} \\
\text { ratio }\end{array}$ & $\begin{array}{l}\mathrm{Ag} \\
(\mathrm{wt} . \%)\end{array}$ & $\begin{array}{l}\mathrm{BET} \text { area } \\
\left(\mathrm{m}^{2} \mathrm{~g}^{-1}\right)\end{array}$ & $\begin{array}{l}\mathrm{V}_{\mu}\left(\mathrm{cm}^{3} \mathrm{~g}^{-}\right. \\
{ }^{-}\end{array}$ & $\begin{array}{l}\mathrm{S}_{\text {EXT }} \\
\left(\mathrm{m}^{2} \mathrm{~g}^{-}\right. \\
\left.{ }^{-}\right)\end{array}$ \\
\hline $\mathrm{X} 1$ & $\mathrm{X}$ & $180-230 \mathrm{~nm}$ & 1.2 & 10.8 & 691 & 0.30 & 62 \\
$\mathrm{X} 2$ & $\mathrm{X}$ & $1.2-2.2 \mu \mathrm{m}$ & 1.2 & 10.7 & 687 & 0.31 & 42 \\
$\mathrm{~B} 1$ & beta & $200-300 \mathrm{~nm}$ & 13.4 & 2.4 & 639 & 0.22 & 186 \\
$\mathrm{~B} 2$ & beta & $400-500 \mathrm{~nm}$ & 17.2 & 2.3 & 530 & 0.20 & 108 \\
\hline
\end{tabular}


Table 2. Ag released (ppm) after the 7-minute tests using E. coli as a function of the zeolite type and zeolite concentration.

\begin{tabular}{llll}
\hline & $0.05 \mathrm{mg} \mathrm{ml}^{-1}$ & $0.1 \mathrm{mg} \mathrm{ml}^{-1}$ & $0.5 \mathrm{mg} \mathrm{ml}^{-1}$ \\
\hline $\mathrm{X} 1$ & $0.02 \pm 0.01$ & $0.04 \pm 0.01$ & $0.05 \pm 0.00$ \\
$\mathrm{X} 2$ & $0.11 \pm 0.01$ & $0.14 \pm 0.01$ & $0.15 \pm 0.01$ \\
$\mathrm{~B} 1$ & $1.00 \pm 0.04$ & $1.71 \pm 0.08$ \\
$\mathrm{~B} 2$ & $1.52 \pm 0.24$ & $1.70 \pm 0.07$ & $2.19 \pm 0.11$ \\
\hline
\end{tabular}




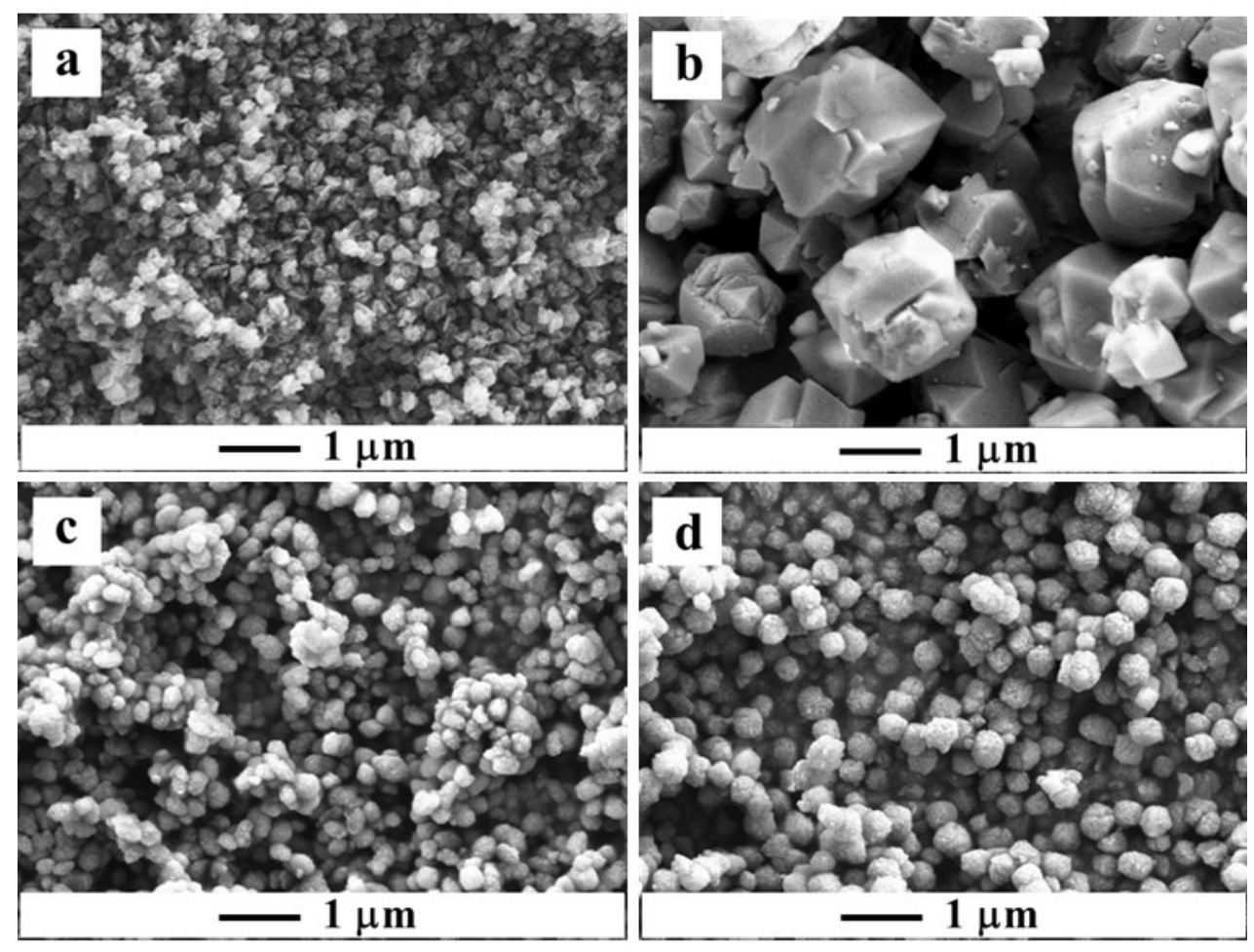

Figure 1 


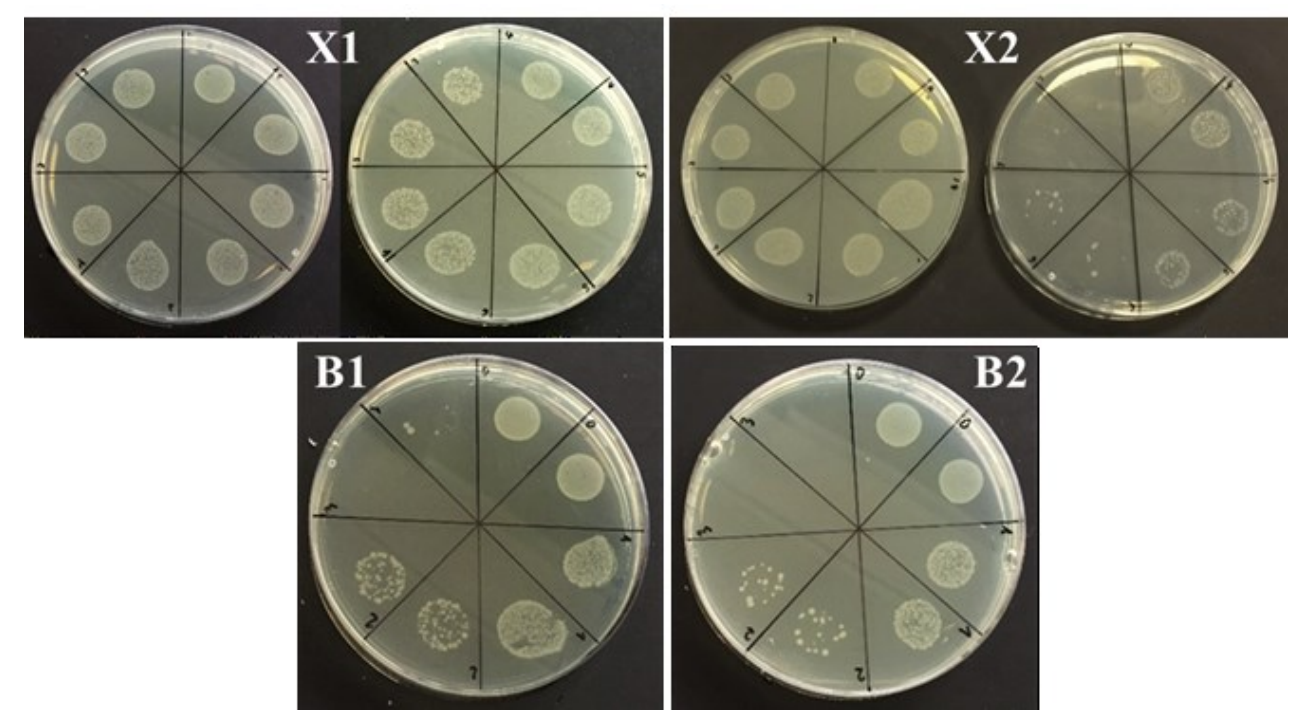

Figure 2 

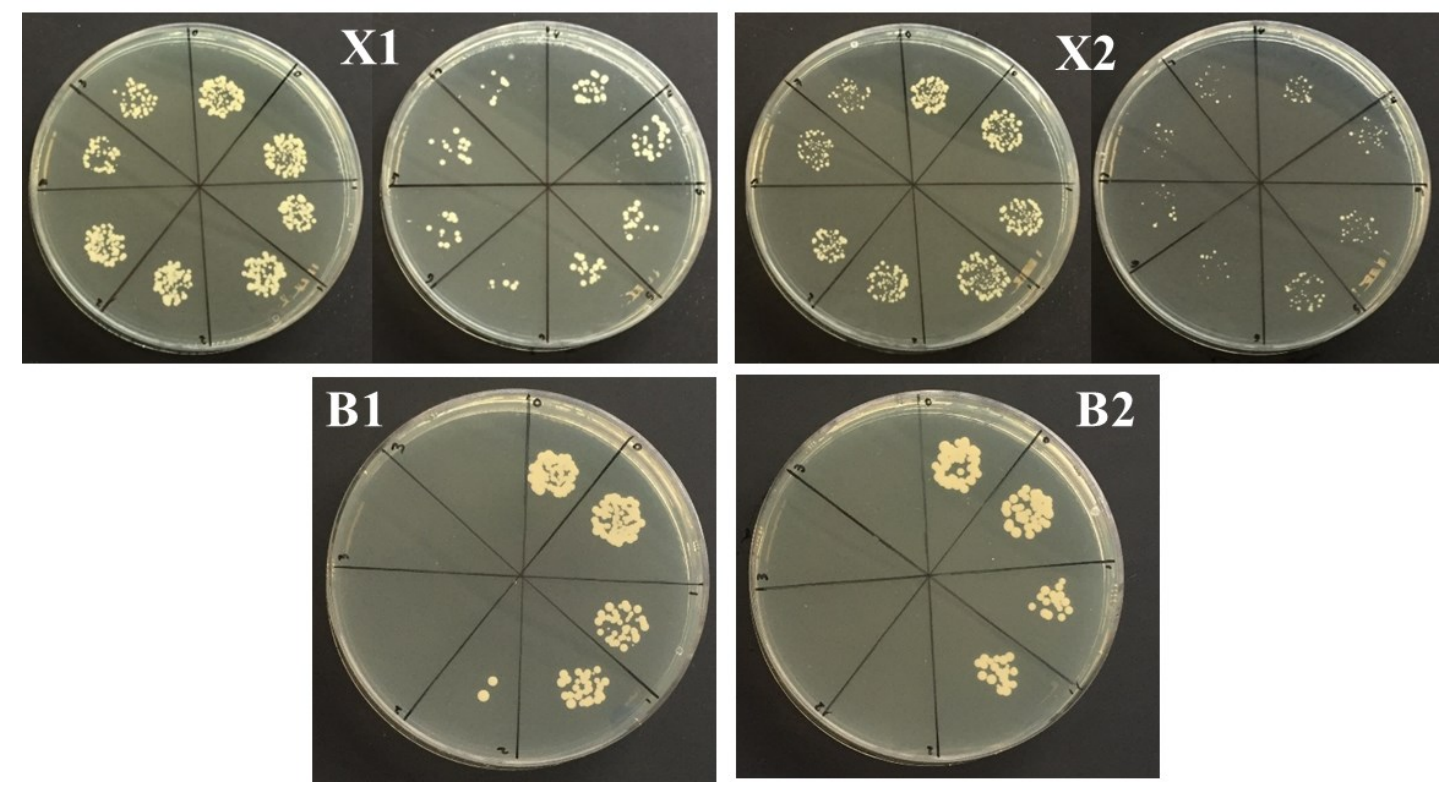

Figure 3 

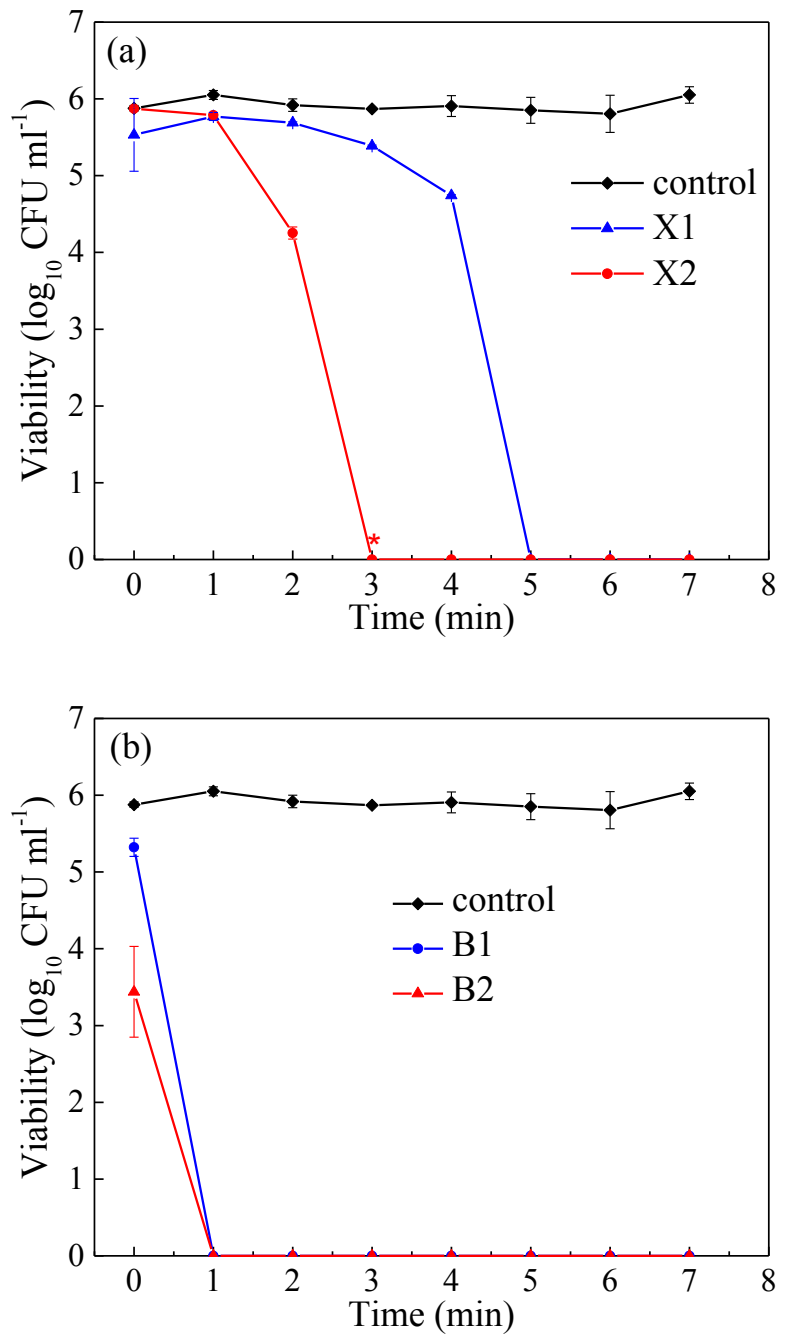

Figure 4 


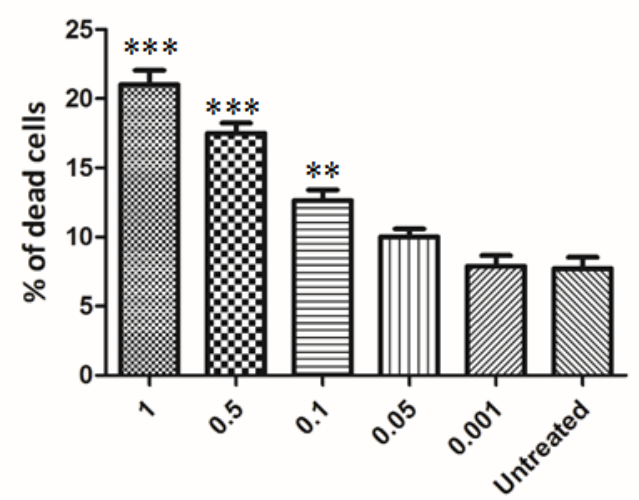

X1 treatments

B1

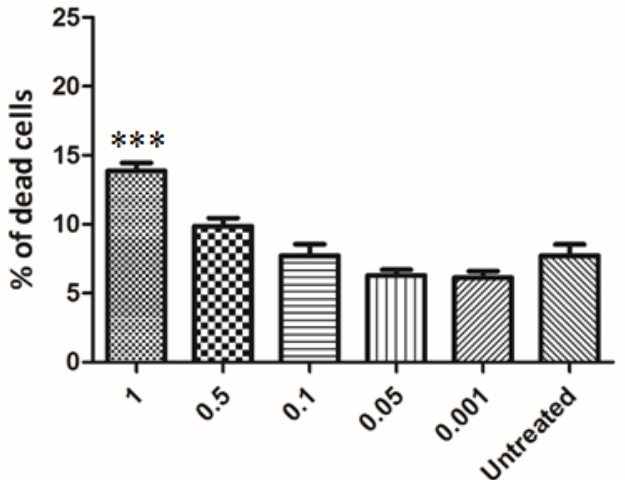

B1 treatments

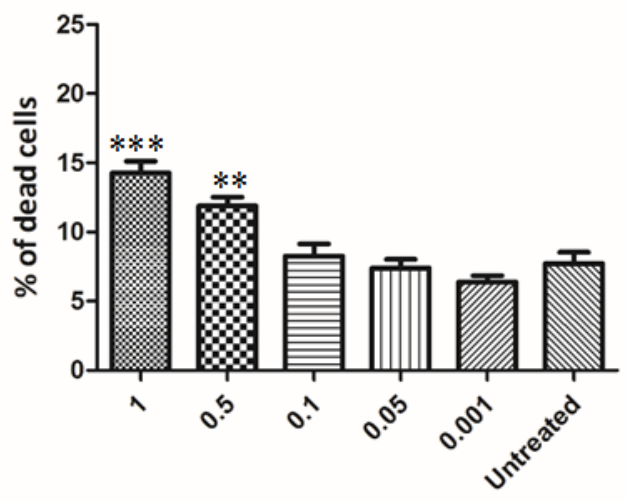

X2 treatments

B2

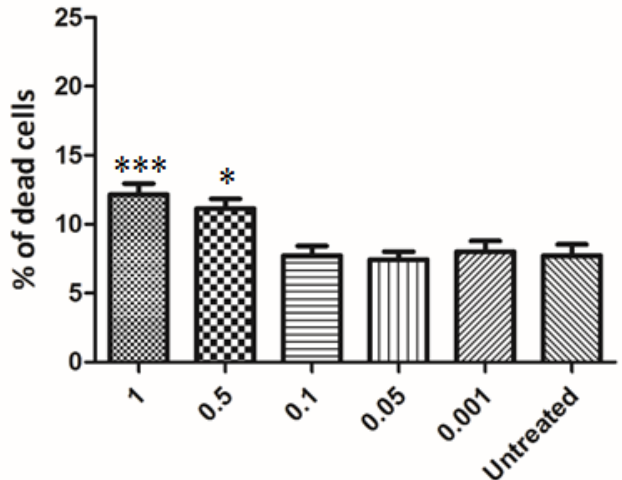

B2 treatments

Figure 5 